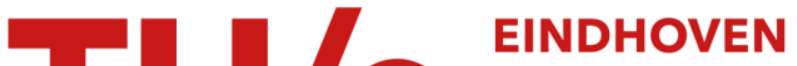 UNIVERSITY OF TECHNOLOGY
}

\section{Analog system-level fault diagnosis based on a symbolic method in the frequency domain}

\section{Citation for published version (APA):}

You, Z., Sanchez-Sinencio, E., \& Pineda de Gyvez, J. (1995). Analog system-level fault diagnosis based on a symbolic method in the frequency domain. IEEE Transactions on Instrumentation and Measurement, 44(1), 2835. https://doi.org/10.1109/19.368107

DOI:

10.1109/19.368107

Document status and date:

Published: 01/01/1995

\section{Document Version:}

Publisher's PDF, also known as Version of Record (includes final page, issue and volume numbers)

\section{Please check the document version of this publication:}

- A submitted manuscript is the version of the article upon submission and before peer-review. There can be important differences between the submitted version and the official published version of record. People interested in the research are advised to contact the author for the final version of the publication, or visit the $\mathrm{DOI}$ to the publisher's website.

- The final author version and the galley proof are versions of the publication after peer review.

- The final published version features the final layout of the paper including the volume, issue and page numbers.

Link to publication

\section{General rights}

Copyright and moral rights for the publications made accessible in the public portal are retained by the authors and/or other copyright owners and it is a condition of accessing publications that users recognise and abide by the legal requirements associated with these rights.

- Users may download and print one copy of any publication from the public portal for the purpose of private study or research.

- You may not further distribute the material or use it for any profit-making activity or commercial gain

- You may freely distribute the URL identifying the publication in the public portal.

If the publication is distributed under the terms of Article 25fa of the Dutch Copyright Act, indicated by the "Taverne" license above, please follow below link for the End User Agreement:

www.tue.nl/taverne

Take down policy

If you believe that this document breaches copyright please contact us at:

openaccess@tue.nl

providing details and we will investigate your claim. 


\title{
Analog System-Level Fault Diagnosis Based on a Symbolic Method in the Frequency Domain
}

\author{
Zhihong You, E. Sánchez-Sinencio, Fellow, IEEE, and Jose Pineda de Gyvez, Member, IEEE
}

\begin{abstract}
Concurrently, a symbolic approach for analog system-level fault diagnosis and a systematic approach to maximize the fault location capability are proposed. This unified approach is realized as a result of combining the simulation before test (SBT) fault dictionary diagnosis method with a symbolic approach. The traditional SBT fault dictionary method is often costly and inefficient because of a high number of simulations, but it can become very efficient when a symbolic approach is employed. This symbolic approach only requires one analysis for circuit topology to generate the network transfer function and a parameter substitution to obtain the frequency response (or time response) of the system. An efficient program is developed to deal with the frequency responses of the system to provide the optimum testing point set, and to automatically generate the fault dictionary. The "distance" between the measurement data and the frequency responses from the fault dictionary is evaluated to determine the diagnosis results. A practical example is presented in order to illustrate the main features of this proposed analog system fault diagnosis approach.
\end{abstract}

\section{INTRODUCTION}

$\mathbf{T}$ THE problem of analog circuit fault diagnosis first attracted researchers' attention in the 1960's, and later became a flourishing research activity because of the advent of modern, complex analog circuits and systems. However, the progress has been slow because there is not any user-oriented, publicly available computer program for analog circuit fault diagnosis such as those for digital circuit diagnosis [1]. The main factors [2]-[4] that make analog circuit fault diagnosis difficult can be summarized as follows:

1) Analog systems are usually nonlinear and have widely spread parameter values. Thus, deterministic methods are often inefficient for modeling these systems. At the same time, analog systems have a continuum of possible failures. It is also difficult to have the same simple, discrete models to cover all possible analog network faults.

2) In analog circuits, a good component may be within tolerance, but not nominal. This implies that an extremely large number of simulations, or a complicated calculation method is often required for analog circuit fault diagnosis.

Manuscript received February 21, 1994; revised June 12, 1994.

Z. You is with Texas Instruments, Inc. MS 3672,8390 LBJ Freeway, Center 1, Dallas, TX 75265 USA.

E. Sánchez-Sinencio and J. Pineda de Gyvez are with the Texas A\&M University, Department of Electrical Engineering, College Station, TX 77843 USA.

IEEE Log Number 940775.
3) Relations between input and output signals in analog circuits are sometimes more complicated as compared to those in digital circuits. These relations in analog circuits are more difficult to model than digital circuit representations, which are based on classical truth tables, and thus, are precise and easy to model.

4) The number of I/O's in analog circuits is small. This implies that analog circuit fault diagnosis requires a great amount of computer time and computer storage as the number of observable/controllable pins is small.

5) There are some inherent interactions between various circuit parameters, which will impede efficient functional verification and diagnosis.

There are many problem formulations depending on the systems under test, e.g., fault models, measurement conditions and the final objective of the fault diagnosis [5]. The key factors in the classification of diagnostic problems are the following:

1) Systems under test [1], [5]

a) Elements contained in the system: RLC or RC; controlled sources; operational amplifiers (OP AMP); operational transconductance amplifiers (OTA); switches and nonlinear elements.

b) Excitation of the systems: DC excitation; sinusoidal excitation, which includes single frequency or multifrequency.

c) Number of exciting sources (independent sources or inputs): Single exciting sources; multiple exciting sources.

2) Fault models [4], [5]

By a fault we mean, in general, any change in the value of an element with respect to its nominal value which can cause the failure of the whole circuit. The fault could be catastrophic (HARD fault) when the faulty element produces either a short circuit or an open circuit, or parametric (SOFT fault) when the faulty element just deviates from its nominal value for a specific design tolerance range. These soft faults could result from manufacturing tolerances, aging, or parasitic effects. Several fault location techniques only address the cases when just one parameter causes the fault. This is referred to as a single fault. In practice the multiple-fault case, which is caused by several faulty parameters, could occur, and recent techniques address this as a difficult case [1], [2]. 
3) Measurements

The measurements can be carried out in DC, frequency or time domains. Within the different domains, voltage measurements or current measurements can be chosen.

4) Final objective of fault diagnosis [3], [4], [6]

In general, analog circuit fault diagnosis has three main objectives: fault detection, fault location and fault identification. Fault detection is the minimum requirement for the fault diagnosis; it answers WHETHER an analog circuit's functionality falls outside design specification. Fault location is the necessary requirement for repairing faulty parts at a later time; it addresses WHERE the faults are. Fault identification is necessary for tuning and adjustment; it answers WHAT the exact value of the deviation is. For these purposes, many fault diagnosis ideas have been developed. The major characteristics of these ideas can be classified into the pattern recognition, parameter identification, fault verification, and approximation techniques.

Two basic methods of analog fault diagnosis are the simulation-before-test (SBT) and the simulation-after-test (SAT) methods [2]. The SBT techniques use a pattern recognition concept [2], which is implemented by simulating the circuit with the possible fault conditions before the actual testing; the results are stored in look-up tables. It can effectively detect and locate hard faults. The fault simulation plays a very important role in this approach. The application of SBT techniques is usually limited to circuits of small or moderate size for the detection of only hard faults. The fault dictionary technique is an SBT method.

All parameter identification and fault verification techniques belong to the SAT approach, which simulates the circuit at the testing time or after the testing time. Parameter identification techniques identify all circuit parameters under the assumption that enough independent measurements are available [7], [8]. These techniques are classified as linear or nonlinear according to the nature of the diagnosis equations. Fault verification techniques can only identify a few faulty elements under the assumption that a few elements are faulty and the rest of the network elements are within design tolerances. Based on this idea, several algorithms have been developed such as the substitution theorem-based technique, the failure bound technique and the network decomposition approach [1], [9]. In the SAT approach there have been various methods which may locate single or multiple, hard or soft faults in circuits of small or relatively large size. However, the complexity and computer time required usually limits its applicability.

The motivation of the research hereby presented is to improve the traditional SBT fault dictionary approach. It is known that the traditional SBT fault dictionary technique is very time consuming and costly because a high number of numerical simulations are required to construct the fault dictionaries of the system under test. But, it might be rendered more useful if an efficient approach could be found to generate fault dictionaries in reasonable amounts of computer time. For this reason, a symbolic approach is introduced during the fault dictionary generation.

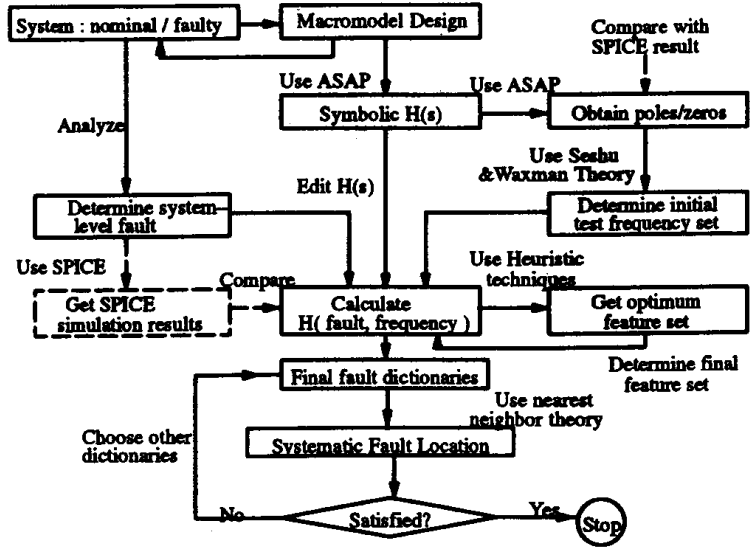

Fig. 1. Symbolic fault diagnosis flow diagram.

The proposed approach uses the symbolic simulator (ASAP) [13] to generate the requested network functions of the circuit under test [15], and then only expression evaluations are required to obtain all the possible faulty responses. Compared to a traditional approach, which uses a numerical simulator (SPICE) to obtain the faulty responses, the proposed approach is more efficient and less costly. It can also deal with single/multiple faults, soft/hard faults at the same time. This reduction in computation time to evaluate the faulty responses is a key contribution of this paper. The other practical contribution is the systematic approach to maximize the fault location capability.

\section{Proposed Fault Diagnosis ApProach}

Nowadays, two main classes of simulators exist. One class is the numerical simulator, such as SPICE, which can be used for nonlinear dc, nonlinear transient and linear ac analysis problems. Even though it is very efficient, it only returns a collection of numbers, in tabular or plot forms. The other class is the symbolic simulator. It can yield the network function in which some, or all, of the circuit elements, $p_{1}, p_{2}, \cdots$, $p_{m}$, along with the complex frequency $s$, are represented by symbolic parameters, as shown in (1)

$$
H\left(s_{1}, p_{1}, p_{2}, \cdots, p_{m}\right)=\frac{N\left(s_{1}, p_{1}, p_{2}, \cdots, p_{m}\right)}{D\left(s_{1}, p_{1}, p_{2}, \cdots, p_{m}\right)} .
$$

The symbolic simulation has noteworthy advantages with respect to the numerical simulation for those applications which require the repetition of a high number of simulations performed on the same circuit topology with the variation of component values and/or frequency [14]-[15]. In these types of applications, the symbolic approach can be used to generate the requested network functions of the analyzed circuit in parametric form. In this way, the circuit analysis is performed only once and, during the fault dictionary generation phase, only a parameter substitution and an expression evaluation are required to obtain the numerical results. Evidently, the function evaluation is much easier and faster than working repeatedly with a network analysis program to perform a full ac analysis.

The flow diagram of the proposed symbolic fault dictionary diagnosis approach is shown in Fig. 1. The dashed lines are 


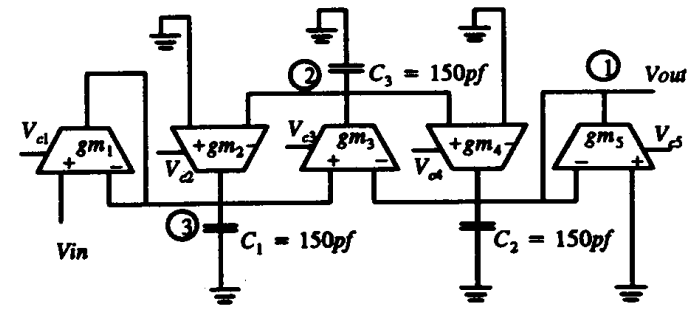

Fig. 2. OTA-C leapfrog lowpass filter.

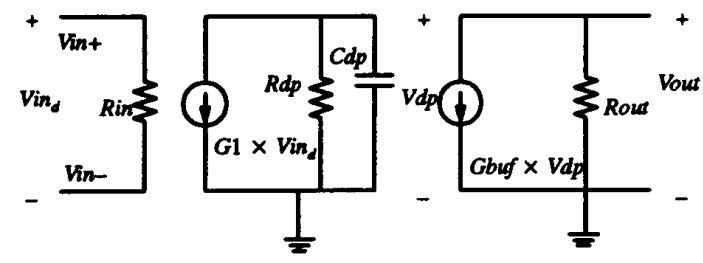

Fig. 3. A simple macromodel for an OTA.

related to SPICE simulations. All these parts (dashed arrows) are only used to verify the new symbolic fault dictionary approach during the research stage. In actual use, SPICE will not be used.

For a system under test, it is necessary to have macromodels for dealing with the system-level faults. These macromodels focus on building-block performance parameters of OP AMP's and OTA's rather than on transistor-level parameters.

Next, a detailed explanation of Fig. 1 is given. Once the macromodels are generated, the symbolic simulator, ASAP, is used to generate the network transfer function, $H(s)$, in which some, or all, of the circuit elements, along with the complex frequency, are represented by symbolic parameters. At the same time, the system-level faults ${ }^{1}$ are determined based on the macromodel circuit, and the initial testing frequencies are chosen according to the Seshu and Waxman theory [2]. Then, a parameter substitution and an expression evaluation are performed to obtain the required numerical frequency responses. The output frequency responses, under all faulty conditions, and together with the frequency testing points, form a recognition matrix. Each column of the recognition matrix is related to a testing frequency point, and each row of the matrix is related to a specific faulty case. An optimum testing-point selection technique [18] is used to make the new approach self-contained. The testing-point selection is a choice with the minimum testing frequency points to maximize the fault diagnosability. Based on the optimum testing points, the fault dictionary can be generated automatically. At this point, the off-line computation is finished.

During the on-line computation, the nearest neighbor rule is used to locate the faults. This rule is based on the idea that a faulty case which has the minimum Euclidean distance with the testing data will be the most likely fault. For an analog system, there are several accessible nodes which can provide different information for fault diagnosis. This fact leads us to propose a systematic fault location approach, which is developed to maximize the fault location capability.

${ }^{1}$ System-level faults are those faults that do not consider actual transistors.

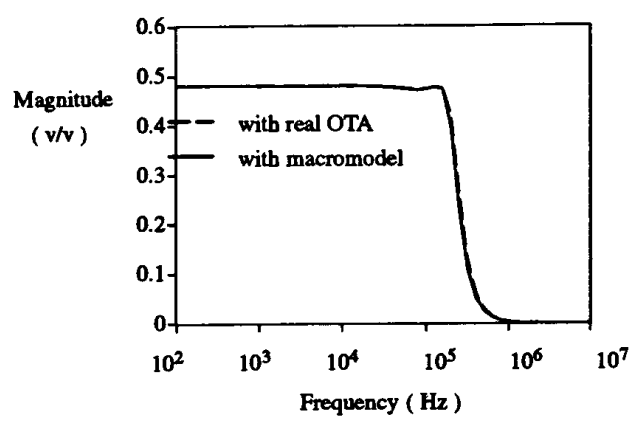

Fig. 4. Comparison between the OTA-C leapfrog lowpass filter with the real OTA and with its macromodel.

Based on the above discussion, it is evident that the proposed symbolic fault diagnosis approach can save the off-line computation time invested in the fault dictionary generation. Undoubtedly, this proposed approach can be more efficient and practical than conventional techniques. Also, fault location capabilities can be maximized using a systematic technique.

\section{Symbolic FAUlt Diagnosis}

\section{A. System Under Test}

In this presentation, we address continuous-time, linear, time-invariant systems, which are composed of lumped passive elements and active devices. These systems can be characterized by (2) or (3) in the Laplace domain:

$$
\begin{aligned}
& H(s)=\frac{Y(s)}{X(s)}=\frac{a_{m} s^{m}+a_{m-1} s^{m-1}+\cdots+a_{0}}{b_{n} s^{n}+b_{n-1} s^{n-1}+\cdots+b_{0}} \\
& H(s)=\frac{Y(s)}{X(s)}=\frac{a_{m}\left(s-Z_{1}\right)\left(s-Z_{2}\right) \cdots k\left(s-Z_{m}\right)}{b_{n}\left(s-p_{1}\right)\left(s-p_{2}\right) \cdots\left(s-p_{n}\right)} .
\end{aligned}
$$

An OTA-C leapfrog lowpass filter is chosen as an example to illustrate the proposed fault diagnosis symbolic method. The topology of the OTA-C leapfrog lowpass filter is shown in Fig. 2. The real OTA used in the OTA-C filter is a tunable OTA [11], which uses the voltage $V_{C_{i}}$ to control the transconductance $g_{m}$ of the OTA, for $i=1, \cdots, 5$.

This approach can address system-level faults, which focus on the behavioral performance of the OP AMP and the OTA. To deal with system-level faults, simple macromodels for the OP AMP and the OTA need to be built. These macromodels should include typical parameters: namely, gain, dominant pole, input impedance and output impedance, to accurately represent the performance of the circuit or subcircuit under test for all faulty conditions.

For the OTA-C leapfrog lowpass filter, the typical onedominant-pole macromodel is shown in Fig. 3. Here, $G_{1}\left(V_{C_{i}}\right)$ $=G_{m}$ represents the transconductance gain; the dominant transconductance pole is $\omega_{p}=1 /\left(R_{d p} * C_{d p}\right), G_{b u f}=1$ and; $R_{\text {in }}$ and $R_{\text {out }}$ characterize the input and output resistances, respectively. When this simple, one-dominant-pole macromodel $^{2}$ is included in a closed-loop configuration, it matches well with the real OTA at the transistor level. Fig. 4 shows the comparison between the OTA-C leapfrog lowpass filter

${ }^{2}$ A more complex OTA macromodel could be used for higher frequency applications. 
TABLE I

Comparison of the EXTRActed Poles/Zeros from ASAP aNd SPICE for the OTA-C Leapfrog LowPass FlLTER Poles/Zeros from ASAP ( rad/sec)

Symbolic pole extraction
$\operatorname{rot}[0]=-488.841 e+3+1.239 e+6 i$
$\operatorname{root}[1]=-488.841 e+3-1.239 e+6 i$
$\operatorname{roo}[2]=-968.288 e+3+0 i$

$S y m b o l i c$ zero extraction
$\operatorname{rot}[0]=-666.6667 e+6+21.838 i$
$\operatorname{root}[1]=-666.6667 e+6-21.838 i$
$\operatorname{rot}[2]=9.014 e+12+1.561 e+13 i$
$\operatorname{rot}[3]=9.014 e+12+1.561 e-13 i$
Poles/Zeros from SPICE ( rad/sec)

with the real OTA subcircuit and with its macromodel. The standard deviation of the difference between the two responses is $\mathbf{0 . 0 5 3}$. The CPU time used for the simulation with the OTA macromodel is about 10 times faster than for the simulation with the OTA at the transistor level.

\section{B. Feasibility Analysis of Using ASAP to Substitute for SPICE}

One of the main advantages of the proposed fault diagnosis approach is to use a symbolic simulator to substitute for the use of numerical simulations during the generation of the fault dictionaries. This will reduce the computational time and make the approach more practical. However, it is necessary to analyze the feasibility of using symbolic simulations to substitute for numerical simulations. We present two sufficient and necessary conditions to do the feasibility analysis.

Condition 1: Poles and Zeros Comparison: Each continuoustime linear time-invariant system can be represented by (3), which is the transfer function characterized by the poles and zeros, and concurrently all these poles/zeros are functions of some, or all, circuit parameters. Parameter deviations change the locations of the poles and zeros, and consequently change the magnitude of the transfer function. This fact implies that the feasibility analysis of using a symbolic simulator can be verified by comparing the numerically and symbolically extracted poles and zeros. Table I shows the comparison of poles/zeros from ASAP and HSPICE for the OTA-C leapfrog

lowpass filter. The results show that there are some differences between the larger poles and zeros. This is due to the fact that we are using a simple OTA macromodel. However, the critical poles and zeros of this system are matching very well with a standard deviations of less than 1.0e-6, see Fig. 4. Based on the fact that mainly the critical poles and zeros affect the system performance, one can conclude that good matching between the poles and zeros from ASAP and SPICE is obtained.

Condition 2: Numerical Frequency Response Comparison: The symbolic transfer function from ASAP can be represented by (2). When $s=j \omega$, the magnitude frequency responses can be calculated by (4), shown at the bottom of the page.

Here, "INT" means integer, and all $a_{i}$ and $b_{j}$ are functions of the circuit parameters.

The flow chart for calculating the frequency response of the system under test is shown in Fig. 5. Two libraries are set to automate the calculation. One is the element library, which includes all possible elements of the system under test. They are capacitors, resistors, OP AMP's and OTA's. The other library is the faulty case library, which includes several possible faulty cases for each kind of element. For example, each OP AMP has several faulty cases, namely, voltage gain " $e$ " deviations from their nominal value, input impedance reductions, and output impedance changes to open circuits. For a given system under test, the faulty cases can be generated automatically by searching the faulty case library. Using the

$$
\mid H(j \omega)=\left(\frac{\left[a_{o}+\sum_{i=1}^{I N T(N / 2)}(-1)^{i} a_{2 i} \omega^{2 i}\right]^{2}+\left[\sum_{i=1}^{I N T(N / 2)}(-1)^{2 i-1} a_{2 i-1} \omega^{1 i-1}\right]^{2}}{\left[b_{o}+\sum_{j=1}^{I N T(N / 2)}(-1)^{j} b_{2 j} \omega^{2 j}\right]^{1}+\left[\sum_{j=1}^{I N T(N / 2)}(-1)^{2 j-1} b_{2 j-1} \omega^{2 j-1}\right]^{2}}\right)^{1 / 2}
$$




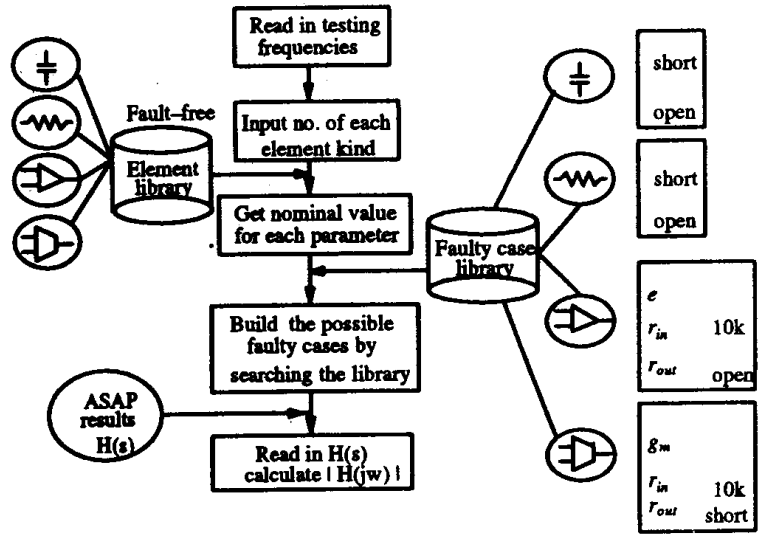

Fig. 5. Flow chart for calculating frequency response.

faulty cases and the testing frequency points, the evaluation of the symbolic transfer function can be done to obtain the frequency responses of the system.

The comparison between ASAP calculations and SPICE simulations using the OTA-C leapfrog lowpass filter are shown in Fig. 6. The standard deviation of the difference is about 0.0003 . These results verify that the symbolic simulator can be used to substitute for SPICE numerical simulations.

\section{Optimum Testing-Point Selection}

One of the most important aspects in the design of fault diagnosis schemes is the testing-point selection. With proper and efficient testing-point selection, diagnosability of faulty components can be increased considerably. Improper or ineffective testing points will increase the number of frequency points needed for testing, thereby increasing the testing time and/or computational facilities required. It will also increase confusion and errors in diagnosability [2]. Testing-point selection [23] is the optimal choice of the minimum number of measurement points while maintaining and/or maximizing the probability of correct diagnosis. The initial testing features are chosen according to the Seshu and Waxman theory, which requires that there must be at least one test break point below the "lowest nonzero" break point, and one between the successive break points [2], [18]. The rationale behind this choice is that all poles and zeros of the network are functions of the network parameters. Parameter deviations cause changes in the locations of the poles and zeros, and consequently change the magnitude of the transfer function. Here the "lowest nonzero" and the "highest finite" frequency break points depend on the particular poles/zeros distribution and the range of frequencies over which the system is active.

A heuristic optimum testing-point selection, proposed in [18], is used in this symbolic approach for the sake of completeness. This procedure selects a set of testing points without performing the exhaustive search of all subsets of frequency points.

For a given circuit, the fault dictionaries for some accessible nodes are built and stored in a dictionary library. After obtaining measurement data, the corresponding fault dictionary

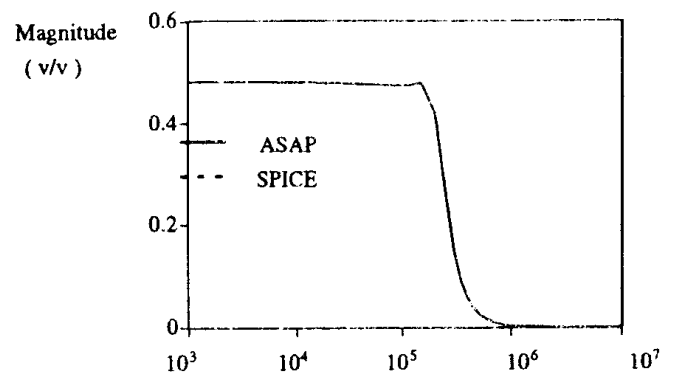

Fig. 6. Comparison hetween frequency responses trom ASAP and SPICE for the OTA-C leapfrog lowpass filker.

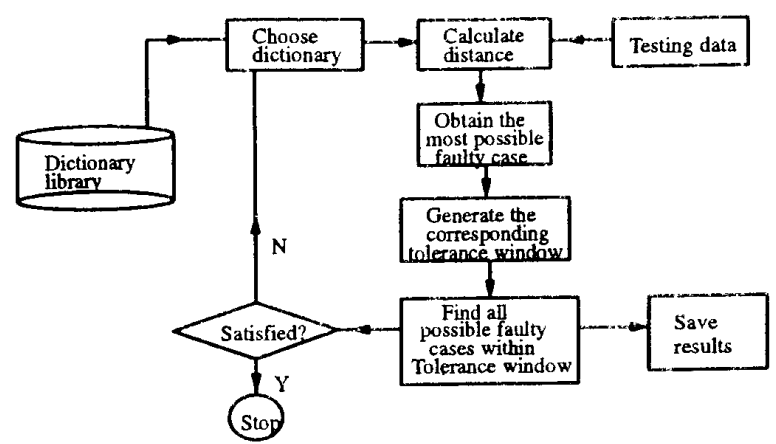

Fig. 7. Flow chart for systenatic fault locition.

is chosen. Then, the nearest neighbor rule is used to locate the most likely faulty case based on the minimum "distance" concept. Possible faulty cases which fail within the tolerance window can be identified and grouped together. If the fault family only has one faulty case, the process is finished; if not, a different dictionary for a different node is chosen, and another fault family is obtained. See Fig. 7 for a flow chart of this procedure. The same procedure is carried out $k$ times, where $k$ is the number of accessible nodes. The final fault location result can be determined as follows:

$$
\begin{aligned}
\text { Fault }= & \text { faulı family (node } 1) \cap \text { fault fanily (node } 2) \\
& \cap \cdots \text { fault family }(\text { node } k)
\end{aligned}
$$

This approach is similar to the ambiguity sets concept introduced in [24]. Rather than using fixed constraints to isolate the faults, the method we implemented makes use of tolerance windows. That is to say, the output responses are considered within a certain standard deviation. This allows us to consider the effect of component tolerances in the final result. Obviously, the wider this window is, the nore fault cases it can include. But on the other hand, a window allows taking into account the regular variations of the fault-free response. Cases in which an element is considered faulty under the fixed-constraint value approach, may actually not be faulty if they fall within the tolerance window of the faultfree response. Furthermore, our fault diagnosis approach uses a symbolic analysis not used in [24]. 
TABLE II

Initial Testing-Point Set for the OTA-C LeAPfrog LowPAss Filter $(\mathrm{kHz})$

\begin{tabular}{|cccccc|}
\hline 1 & 2 & 3 & 4 & 5 & 6 \\
7 & 8 & 9 & 10 & 50 & 100 \\
150 & 200 & 250 & 300 & 350 & 400 \\
$\mathbf{4 5 0}$ & 500 & $\mathbf{5 5 0}$ & $\mathbf{6 0 0}$ & $\mathbf{6 5 0}$ & $\mathbf{7 0 0}$ \\
$\mathbf{7 5 0}$ & $\mathbf{8 0 0}$ & $\mathbf{8 5 0}$ & $\mathbf{9 0 0}$ & $\mathbf{9 5 0}$ & 1000 \\
3250 & $\mathbf{5 5 0 0}$ & $\mathbf{7 7 5 0}$ & $\mathbf{1 0 0 0 0}$ & & \\
\hline
\end{tabular}

TABLE III

Optimum Testing-Point Set for the OTA-C Leapfrog Lowpass Filter $(\mathrm{kHz})$

\begin{tabular}{|c|ccccc|c|}
\hline Node & \multicolumn{7}{|c|}{ Optimum Testing Point Set } & No. of Points \\
\hline & 10 & 50 & 100 & 150 & 200 & \\
1 & 250 & 300 & 350 & 400 & 450 & 15 \\
& 500 & 3250 & 5500 & 7750 & 10000 & \\
\hline 2 & 4 & 6 & 9 & 150 & 250 & 6 \\
\hline 3 & 3250 & & & & & 9 \\
\hline
\end{tabular}

\section{Diagnosis Results}

Based on the rationale presented before, the fault dictionary should be built for each accessible node of the circuit. After the fault dictionaries of all accessible nodes in the circuit are built, the off-line computation has been finished. Then, the online computation of testing data can be carried out to locate the faults.

Step 1: Off-Line Computation Results: Based on Seshu and Waxman's theory, the initial testing-point set for the OTAC leapfrog lowpass filter is shown in Tablc II, which totally includes 34 frequency points. Table III shows the optimum frequency testing-point set for each accessible node in the OTA-C leapfrog lowpass filter, which is shown in Fig. 2. After the optimum testing-point sets are determined, the fault dictionary for each node is generated automatically.

Step 2: On-Line Computation Results: In this presentation, two kinds of testing data are discussed. One of them, generated from SPICE simulations using the real OTA, is used to test the theoretical feasibility of the proposed solution.

In the data set 38 faults were generated consisting of short circuits, opens, and excessive parameter value variations. The other testing data was obtained from actual measurements of a test chip to verify the practicality.

1) Using SPICE Simulation Data: For the OTA-C leapfrog lowpass filter, the simulation data is generated from the filter with the real OTA subcircuit. Some diagnosis results are shown in Table IV.

In an analog system, the output response has its specification tolerance range because of the circuit parameter tolerance and the inaccuracies in the measurement [19]. The tolerance column in Table IV shows the specification tolerance range (also called tolerance window).

2) Using Measurement Data of OTA-C Leapfrog Lowpass Filter: In order to verify the practicality of this proposed symbolic fault diagnosis approach, the actual testing data of the OTA-C leapfrog lowpass filter is used. During the online testing, several possible faulty cases are produced. For a capacitor, a fault can be produced by adding or reducing one or more capacitors to make its value change. For an OTA, the control voltage can be used to adjust the gain to a faulty
TABLE IV

SOME Diagnosis Results For THE OTA-C LEAPFrog LOWPASS FILTER WITH SPICE SiMULATION DATA

\begin{tabular}{|c|c|c|c|c|c|c|}
\hline \multirow{2}{*}{\multicolumn{2}{|c|}{$\begin{array}{c}\text { Faulty case } \\
\text { of testing data }\end{array}$}} & \multicolumn{5}{|c|}{ Program diagnosis results } \\
\hline & & Tolerance & Node & \multicolumn{2}{|c|}{ Fault families } & Final result \\
\hline Fo & & $\pm 20 \%$ & $\begin{array}{l}1 \\
2 \\
3 \\
\end{array}$ & \multicolumn{2}{|c|}{$\begin{array}{l}\text { F0 } \\
\text { F0, F25 } \\
\text { F0, F5, F6, F22, F25 }\end{array}$} & Fo \\
\hline FI & & $\pm 5 \mathscr{x}$ & $\begin{array}{l}1 \\
2 \\
3\end{array}$ & \multicolumn{2}{|c|}{$\begin{array}{l}\text { F1, F5 } \\
\text { F1 } \\
\text { F1 }\end{array}$} & F1 \\
\hline F14 & & $\pm 20 \%$ & $\begin{array}{l}1 \\
2 \\
3\end{array}$ & \multicolumn{2}{|l|}{$\begin{array}{l}\text { F14 } \\
\text { F14 } \\
\text { F14 }\end{array}$} & F14 \\
\hline F18 & & $\pm 20 \%$ & $\begin{array}{l}1 \\
2 \\
3 \\
\end{array}$ & \multicolumn{2}{|c|}{$\begin{array}{l}\text { F18 } \\
\text { F8, F18, F24, F36, F37 } \\
\text { F12, F18, F35 }\end{array}$} & F18 \\
\hline F27 & & $\pm 20 \%$ & $\begin{array}{l}1 \\
2 \\
3\end{array}$ & \multicolumn{2}{|l|}{$\begin{array}{l}\text { F27 } \\
\text { F27 } \\
\text { F27 }\end{array}$} & F27 \\
\hline $\begin{array}{l}\text { F0 } \\
\text { F1 } \\
\text { F5 } \\
\text { F8 } \\
\text { F12 } \\
\text { F14 } \\
\text { F18 }\end{array}$ & \multicolumn{3}{|c|}{$\begin{array}{l}\text { fanlt free case } \\
+50 \% \text { variation in } C_{1} \\
+50 \% \text { variation in } C_{2} \\
+10,000 \% \text { variation in } C_{2} \\
+10,000 \% \text { variation in } C_{3} \\
-50 \% \text { variation in } 8 \mathrm{ml} \\
-90 \% \text { variation in } 8 \mathrm{~m} 2\end{array}$} & $\begin{array}{l}\text { F22 } \\
\text { F24 } \\
\text { F25 } \\
\text { F27 } \\
\text { F35 } \\
\text { F36 } \\
\text { F37 }\end{array}$ & \multicolumn{2}{|c|}{$\begin{array}{l}+50 \% \text { variation in } \mathrm{g}_{\mathrm{m} 4} \\
-90 \% \text { variation in } \mathrm{g}_{\mathrm{m} 4} \\
+50 \% \text { variation in } \mathrm{gms} \\
-90 \% \text { variation in } \mathrm{g}_{\mathrm{ms}} \\
\mathrm{r}_{\mathrm{o} 3} \text { set to } 100 \\
\mathrm{r}_{\mathrm{o} 4} \text { set to } 100 \\
\mathrm{r}_{\mathrm{o}} \text { set to } 100\end{array}$} \\
\hline
\end{tabular}

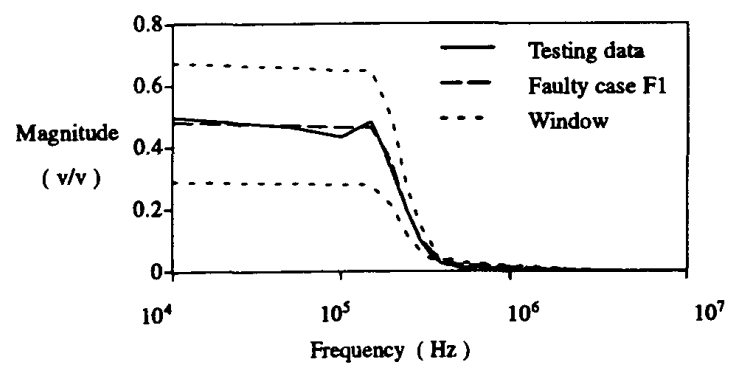

Fig. 8. Diagnosis for actual testing data.

case. After a certain faulty case is generated, the magnitude frequency responses under the optimum feature points are tested for each accessible node, and then diagnosed by using the corresponding dictionary.

The fault case $\mathrm{F} 1$, corresponding to a $50 \%$ variation of $C_{1}$ from its nominal value, is chosen to illustrate the approach. Fig. 8 shows the magnitude frequency response for node 1 under the optimum feature set, which has 15 frequency points. By using the fault location approach with the $+40 \%$ specification tolerance window, the most likely faulty case and its fault family are obtained. Here, the diagnosis result shows that the most likely faulty case is Fl, and the fault family includes F1, F5, F9, and F32. Diagnosis results for the OTA-C leapfrog lowpass filter from actual measurement data are shown in Table V. These results verify the feasibility of the proposed approach.

\section{CONCLUSIONS}

A new symbolic method based on a conventional analog system fault diagnosis approach has been presented. This approach combines the SBT fault dictionary diagnosis method with a symbolic simulator, ASAP, to locate system-level faults 
TABLE V

SOME Diagnosis Results for the OTA-C LEAPFrog

Lowpass Filter from actual Measurement Data

\begin{tabular}{|c|c|c|c|c|}
\hline \multirow{2}{*}{$\begin{array}{l}\text { Faulty case } \\
\text { of testing data }\end{array}$} & \multicolumn{4}{|c|}{ Propram diagnosis results } \\
\hline & Tolerance & Node & Fault families & Final resul \\
\hline Fo & $\pm 30 \%$ & $\begin{array}{l}1 \\
2 \\
3\end{array}$ & $\begin{array}{l}\text { F0, F16, F25 } \\
\text { F0, F6,F16,F22,F29,F31 } \\
\text { F0 }\end{array}$ & F0 \\
\hline F1 & $\pm 40 \%$ & $\begin{array}{l}1 \\
2 \\
3\end{array}$ & $\begin{array}{l}\text { F1, F5, F9, F32 } \\
\text { F1, F9, F14 } \\
\text { F1, F7, F29, F30, F31 }\end{array}$ & F1 \\
\hline F14 & $\pm 20 \%$ & $\begin{array}{l}1 \\
2 \\
3 \\
\end{array}$ & $\begin{array}{l}\text { F14 } \\
\text { F14 } \\
\text { F14 }\end{array}$ & F14 \\
\hline F18 & $\pm 20 \%$ & $\begin{array}{l}1 \\
2 \\
3 \\
\end{array}$ & $\begin{array}{l}\text { F18 } \\
\text { F8, F18, F24, F36, F37 } \\
\text { F12, F18, F35 }\end{array}$ & F18 \\
\hline F27 & $\pm 50 \%$ & $\begin{array}{l}1 \\
2 \\
3\end{array}$ & $\begin{array}{l}\text { F22, F26, F27 } \\
\text { F27 } \\
\text { F27 }\end{array}$ & F27 \\
\hline
\end{tabular}

\begin{tabular}{|c|c|c|c|}
\hline Fo & fault free case & F24 & $-90 \%$ variation in $\mathrm{g}_{\mathrm{m} 4}$ \\
\hline F1 & $+50 \%$ variation in $C_{1}$ & F25 & $+50 \%$ variation in $\mathrm{gms}_{\mathrm{m}}$ \\
\hline F5 & $+50 \%$ variation in $C_{2}$ & F26 & $-50 \%$ variation in $\mathrm{g}_{\mathrm{m} 5}$ \\
\hline F6 & $-50 \%$ variation in $\mathrm{C}_{2}$ & F27 & $-90 \%$ variation in $\mathrm{g}_{\mathrm{ms}}$ \\
\hline F7 & $-100 \%$ variation in $\mathrm{C}_{2}$ & F29 & $\mathrm{r}_{\mathrm{in} 2}$ set to 10,000 \\
\hline F9 & $+50 \%$ variation in $\mathrm{C}_{3}$ & F30 & $r_{\text {in3 } 3}$ set to 10,000 \\
\hline F12 & $+10,000 \%$ variation in $\mathrm{C}_{3}$ & F31 & $\mathrm{r}_{\mathrm{in} 4}$ set to 10,000 \\
\hline F14 & $-50 \%$ variation in $\mathrm{gml}$ & F35 & $T_{03}$ set to 100 \\
\hline F16 & $+50 \%$ variation in $g_{\mathrm{m} 2}$ & F36 & $r_{04}$ set to 100 \\
\hline 1 & $-90 \%$ variation in $\mathrm{gm}_{\mathrm{m} 2}$ & F37 & $r_{0}$ set to \\
\hline & $+50 \%$ variation in & & \\
\hline
\end{tabular}

TABLE VI

CPU TIME For OfF-Line CoMputation (OTA-C Leapfrog LowPass Filter)

\begin{tabular}{|c|c|c|c|}
\hline & Symbolic method & \multicolumn{2}{|c|}{$\begin{array}{l}\text { General SBT fault } \\
\text { dictionary method }\end{array}$} \\
\hline Transfer function. & $0.3 \mathrm{sec}$ & & - \\
\hline $\begin{array}{l}\text { Initial } \\
\text { recognition matrix }\end{array}$ & $\begin{array}{ll}\text { reading netlist } 0.4 \mathrm{sec} \\
\text { ckt. evaluation } 2.2 \mathrm{sec}\end{array}$ & HSPICE & $\begin{array}{l}38 \times 2.0 \mathrm{sec} \\
+\mathrm{t} 1 \\
\end{array}$ \\
\hline $\begin{array}{l}\text { Optimum feature set } \\
\text { and } \\
\text { fault dictionary }\end{array}$ & OPTIMUMF $0.2 \mathrm{sec}$ & OPTIMUMF & $0.2 \mathrm{sec}$ \\
\hline Total & $3.1 \mathrm{sec}$ & & $76.2 \mathrm{sec}+\mathrm{t} 1$ \\
\hline
\end{tabular}

in continuous-time, linear, and time-invariant systems. The conventional SBT fault dictionary method can be costly and inefficient because of the immense number of simulations. But, it becomes very efficient when a symbolic approach is used. This approach permits us to automatically obtain the optimum measurement feature set and generate the fault dictionaries. The nearest neighbor rule is used for fault isolation, and a systematic approach has been developed to maximize the fault isolation capability.

Efficiency of this new symbolic approach can be assessed from Table VI, which shows the measured CPU times for offline computation compared to the conventional SBT fault dictionary method. READCF and CIRCUIT are two C-programs to edit the ASAP symbolic results and to generate the initial recognition matrix, respectively. It is clear that the new symbolic approach can deal with hard/soft faults at the same time and reduce off-line computation.

The above CPU times are measured for the OTA-C leapfrog lowpass filter. Its initial recognition matrix includes 38 faulty cases, which means that 38 SPICE simulations have to be done
TABLE VII

COMParison BetweEn the NEW SyMbolic APPROACH AND THE General SBT Fault Dictionary APProach

\begin{tabular}{|c|cccccc|}
\hline & \multicolumn{2}{|c}{ On-line } & Off-line & Test & Types of & Network \\
computation & computation nodes & faults & type \\
\hline $\begin{array}{c}\text { General } \\
\text { fault } \\
\text { dicrionary }\end{array}$ & minimal & high & limited & $\begin{array}{l}\text { single } \\
\text { hard }\end{array}$ & $\begin{array}{c}\text { linear/ } \\
\text { nonlinear }\end{array}$ \\
\hline $\begin{array}{c}\text { New symbolic } \\
\text { approach }\end{array}$ & minimal & moderate & limited & $\begin{array}{l}\text { multiple } \\
\text { hard/soft }\end{array}$ & linear \\
\hline Goals & minimal & moderate & limited & multiple & general \\
\hline
\end{tabular}

when using the conventional SBT fault dictionary method. Table VI shows that the symbolic approach is more than 20 times faster than the conventional method. In Table VI, $t 1$ is the time needed for editing SPICE results to generate the recognition matrix. A general comparison between the common SBT fault dictionary method and this new approach is shown in Table VII.

\section{ACKNOWLEDGMENT}

The authors want to thank the Analog Microelectronics Group from the Centro Nacional Microelectronica, Seville, and in particular, Dr. Angel Rodríguez-Vázquez for giving us access to a preliminary version of ASAP.

\section{REFERENCES}

[1] R. W. Liu, Ed., Selected Papers on Analog Fault Diagnosis. New York: IEEE Press, 1987

[2] J. W. Bandler and A. E. Salama, "Fault diagnosis of analog circuits," Proc. IEEE, vol. 73, pp. 1279-1324, Aug. 1985.

[3] M. Slamani and B. Kaminska, "Analog circuit fault diagnosis based on sensitivity computation and functional testing," IEEE Design Test of Computer, vol. 9, pp. 30-39, Mar., 1992.

[4] A. Walker, W. E. Alexander, and P. K. Lala, "Fault diagnosis in analog circuits using element modulation," EEE Design Test of Computers, vol. 9, pp. 19-29, March, 1992.

[5] T. Ozawa, Analog Methods Computer-Aided Circuit Analysis Diagnosis. New York, 1989.

[6] J. Rutkoski and A. Macura, "Multiple fault location in AC circuits," IEE Proc. Electron. Circuits Syst., vol. 133, pp. 279-284, Dec. 1986.

[7] A. T. Johnson, Jr., "Efficient fault analysis in linear analog circuits," IEEE Trans. Circuits Syst., vol. CAS-26, pp. 475-484, July 1979.

[8] A. E. Salama and F. Z. Amer, "Parameter identification approach to fault diagnosis of switched capacitor circuits," IEE Proc. Electron. Circuits Syst., vol. 139, pp. 467-472, Feb. 1991.

[9] A. A. Hatzopoulos and J. M. Kontoleon, "Efficient fault diagnosis in analogue circuits using a branch decomposition approach," IEE Proc. Electron. Circuits Syst., vol. 134, pp. 149-157, Aug. 1987.

[10] V. Visvanathan, E. Szeto, and A. Tits, "A robust simulation-before-test technique for DC analog fault diagnosis," Proc. 1984 Int. Symp. Circuits Systems, vol. 2, pp. 689-692, May 1984.

[11] R. Sadkowski, "Tuning CMOS monolithic continuous-time leapfrog filter structures," M.Sc. thesis, Dept. Elec. Eng., Texas A\&M University, College Station, Aug. 1992.

[12] N. Nagi and J. A. Abraham, "Hierarchical fault modeling for analog and mixed-signal circuits," IEEE VLSI Test Symp., vol. 1, pp. 96-101, 1992.

[13] F. V. Fernandez, A. Rodriguez-Vazquez, and J. L. Huertas, "Interactive $\mathrm{AC}$ modeling and characterization of analog circuits via symbolic analysis," Analog Integrated Circuits Signal Processing, vol. 1, pp. 183-208, 1991.

[14] G. G. E. Gielen, H. C. C. Walscharts, and W. M. C. Sansen, "ISAAC: A symbolic simulator for analog integrated circuits," IEEE J. Solid-State Circuits, vol. 243, pp. 1587-1597, Dec. 1989.

[15] S. Manetti and M. C. Piccivilli, "Symbolic simulators for the fault diagnosis of nonlinear analog circuits," Analog Integrated Circuits Signal Processing, vol. 3, pp. 59-72, June 1993. 
[16] F. Vidal Fernandez, "Tecnicas de analisis simbolico para el modelado y diseño de circuitos integrados analogicos," Ph.D. Thesis, Facuitad de Fisica, Universidad de Sevilla, Spain, 1992.

[17] S. Manetti, "New approach to automatic symbolic analysis of electric circuits," IEE Proc. Electron. Circuits Syst., vol. 138, pp. 22-28, Feb. 1991.

[18] K. C. Varghese, J. Hywel Williams, and D. R. Towill, "Computer aided feature selection for enhanced analogue system fault location," Pattern Recognition, vol. 10, pp. 265-280, Feb. 1978.

[19] L. Milor and V. Visvanathan, "Detection of catastrophic faults in analog integrated circuits," IEEE Trans. Computer-Aided Design, vol. 8, pp. 114-130, Feb. 1989.

[20] G. G. E. Gielen, H. C. C. Walscharts, and W. M. C. Sansen, "Analog circuit design optimization based on symbolic simulation and simulated annealing," IEEE J. Solid-State Circuits, vol. 25, pp. 707-713, June 1990.

[21] M E. Zaghloul and D. Gobovic, "Single fault diagnosis of nonlinear resistive networks," IEE Proc. Electron. Circuits Syst., vol. 134, pp. 38-44, Feb. 1987.

[22] A. E. Salama and M. I. Elmasry, "Fault characterization, testing considerations, and design for testability of BICMOS logic circuits," IEEE J. Solid-State Circuits, vol. 27, pp. 944-947, June 1992.

[23] J. L. Huertas, "Test and design for testability of analog and mixed-mode integrated circuits: theoretical aspects and pragmatical approaches," selected topics in Circuits Systems, D. G. Haigh, J. L. Huertas, P. A. Humblet, and M. Kunt, Eds. New York: Elsevier Press, 1993, pp. 75-156.

[24] P. U. Lin and Y. S. Elcherif, "Analogue circuits fault dictionary-New approaches and implementation," Int. J. Circuit Theory Appl., vol. 13, pp. 149-172, 1985.

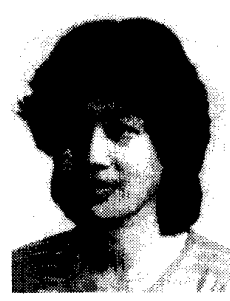

Zhiyong You was born in Beijing, People's Republic of China. She received the B.S. and M.S. degrees in electrical engineering from Tsinghua University, in 1987 and 1989 , respectively. She received the M.Sc. degree from Texas A\&M University, in 1993 From 1989 to 1990 , she worked in China Technology Company, as an Engineer. She then worked in China-American Bausch-Lomb Contact Lens Inc as a Manager Assistant. She is currently employed by Texas Instruments, Inc., Dallas, TX.

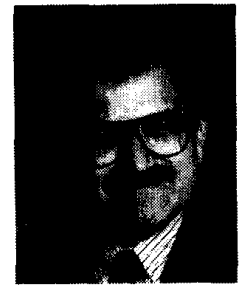

Edgar Sánchez-Sinencio (S'72-M'74-SM'83F'92) was born October 27, 1944, in Mexico City, Mexico. He received the B.Sc. degree in communications and electronic engineering from the National Polytechnic Institute of Mexico, the M.S. degree from Stanford University, Stanford, $\mathrm{CA}$, and the $\mathrm{Ph} . \mathrm{D}$. degree from the University of Illinois at Champaign-Urbana, in 1966, 1970, and 1973 , respectively.

$\mathrm{He}$ was a member of the Board of Governors, IEEE Circuits and Systems Society from 1990-1992, serving as Chairman in 1991 and Chairman Elect. in 1990; the IEEE CAS Technical Committee on Neural Systems and Applications; Associate Editor of the IEEE Trans. ON CIRCUITS AND SYSTEMS from 1985 to 1987, and the IEEE Trans. ON NEURAL NETwORKS from 1990-1993; Associate Editor of the IEEE CIRCUITS AND DEviCEs MAGAZINE (1985-1988); General Chairman of the 26th Midwest Symposium CAS in Puebla, Mexico (1983); a member IEEE CAS Technical Committee on Analog Signal Processing; Associate Editor, IEEE CAS MAGAZINE (1983-1984); and Guest Editor, Special Issues on Neural Network Circuit Implementation, IEEE TRANS. ON NeURAL Networks, March 1991 and May 1992.

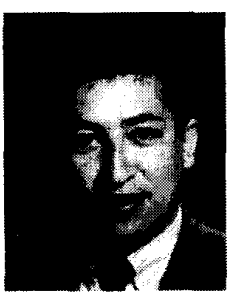

Jose Pineda de Gyvez (S'88-M'90-S'91-M'91) received the degree in electronic systems engineering from the Technological Institute of Monterrey, Monterrey, Mexico, the M.Sc. degree from the National Institute of Astrophysics Optics and Electronics, Mexico, and the Ph.D. from Eindhoven University of Technology, Eindhoven, The Netherlands, in 1982, 1984, and 1991, respectively.

He was a Junior Scientist with the Foundation for Fundamental Research on Matter, The Netherlands, from 1986 to 1991, working on CAD for yield, defect, and fault modeling. He is currently an Assistant Professor in the Department of Electricia Engineering and holds a joint Faculty appointment with the Department of Computer Science, Texas A\&M University, College Station. He is the author of Integrated Circuit Defect Sensitivity: Theory and Computational Models (Kluwer).

Dr. Pineda is a member of the ACM and IEEE Circuits and Systems Society. 